\title{
ECONOMÍA Y FUERZAS ARMADAS
}

\author{
Dr. Pablo Lucio Paredes*
}

$\mathrm{H}$

ay muchas aristas al problema de la relación entre economía y las Fuerzas Armadas, siendo el primero y fundamental un tema de orden político, ¿cuál es el rol que la sociedad asigna a sus ejércitos, y cuál es el rol que las Fuerzas Armadas quieren ocupar en el país? No necesariamente estas dos visiones coinciden, más bien dicho, en el Ecuador actual, es evidente que esas visiones son congruentes. La sociedad civil aparentemente desearía confinarlas a un rol de defensa de las fronteras con el máximo de restricción presupuestaria posible, mientras que la visión propia tiende más bien a una ocupación cada vez más grande del espectro político, social y económico.

Esto se basa en una especie de interpretación mesiánica de su rol en la sociedad (supuesta menos corrupción en su interior, más eficiencia, mejor visión estratégica, poca influencia de la política partidista) y en las alianzas que han ido construyendo por su labor social (sobre todo el Ejército con las comunidades indígenas).

La presencia democrática de un militar en el gobierno (aunque su inicio en la vida pública sea sujeto a mil dudas por el sendero golpista que lo acompañó) y la gran cantidad de militares activos o pasivos que hoy ocupan la cúpula y los intersticios medios y bajos de la estructura estatal, sin duda profundizan y van a profundizar esta tendencia... A no ser que un desastroso manejo del Estado y la economía, más bien termine bruscamente con este espejismo idílico.

La propia sociedad civil es dubitativa en su posición: por un lado quiere restringir el ámbito de la acción militar y por otro, tiende a buscar esa misma fuerza cuando se encuentra ante conflictos políticos (las Fuerzas Armadas como dirimente político último) o ante la incapacidad para organizar esquemas operativos concretos (caso de la presencia en las aduanas en los últimos años).

\footnotetext{
*Analista económico.
} 
Desde el punto de vista presupuestario, estas visiones tan desiguales y marcadas implican escenarios totalmente diferentes. Para la sociedad civil, el final del conflicto peruano debe significar inevitablemente una menor carga de gasto e inversión, que difícilmente puede ser compensada por los riesgos del conflicto colombiano, pero al mismo tiempo, exige unas Fuerzas Armadas siempre listas a atender otro tipo de problemas.

Para las Fuerzas Armadas, el conflicto en la frontera norte requiere de recursos iguales o incluso superiores a los que antes se requerían, si se quiere evitar infiltraciones y presiones internas en el país y, obviamente, los demás aspectos en que se siente su presencia como indispensable requieren de mayores aspectos de la comunidad.

Existen por lo menos tres problemas en la lógica económica de las Fuerzas Armadas, que deben ser enfrentados en el país:

- Presupuestos basados en los objetivos que el país defina.

- Priorización.

- Transparencia.

Sobre los dos aspectos primeros ha esbozado algunos comentarios inicialmente, una mayor profundización de los objetivos, prioridades y sus implicaciones, es un tema para la sociedad en su conjunto y para los especialistas en este delicado ámbito (en esta misma revista se encontrarán varios elementos de reflexión que ayuden en esa dirección).

Me voy a centrar en la transparencia que, como tal, requiere de algunas reflexiones:

1.- Todo presupuesto de las Fuerzas Armadas debe ser aprobado por las instancias legislativas. No puede ser, que una serie de "secretos"militares se manejen a nivel de la Junta de Defensa Nacional, donde en general las cosas las cosas ya llegan presentadas, empaquetadas y casi decididas de antemano. Las finanzas militares deben entrar en el mismo paquete que el resto de gastos. La mecánica perversa de tener gastos militares separados del proceso normal de planificación financiera y económica, es uno de los factores del aumento del endeudamiento externo del país. 


\section{2.- Ningún presupuesto puede ser manejado de manera sepa- rada:}

- EI ISSFA (Seguro Social De Las Fuerzas Armadas) tiene que ser sometido a la misma evaluación que el Instituto Ecuatoriano de Seguridad Social (que, hay que reconocerlo, tampoco es controlado como debería serlo). Debemos estar conscientes que cualquier déficit, de caja o actuarial, de ese sistema va a ser inevitablemente trasladado al resto de la sociedad. Ya existen indicios de que el ISSFA tiene problemas, como la mayor parte de seguros aquí y en casi todas las partes del mundo, porque hay la tentación (casi inevitable) de olvidar la necesidad de guardar reservas importantes para el futuro. Sin duda que el problema tiene que ser resuelto, pero se lo tiene que integrar a un proceso global de evaluación.

- La DINE (Dirección de Industrias del Ejército) de las Fuerzas Armadas, manejan diversos negocios, pocos ligados directamente a sus funciones naturales y la mayor parte en ámbitos totalmente ajenos. La lógica para hacerlo es triple: por un lado aumenta el poder y presencia de las Fuerzas Armadas en la sociedad. Por otro lado, les permite generar recursos propios para su funcionamiento. Finalmente, les admite independizarse de las decisiones políticas del Congreso. Pero, ¿sucede eso realmente? ¿Cuánto aportan las empresas al financiamiento militar? ¿Cuál es su grado de eficiencia? Se ha vendido el lema de que las Fuerzas Armadas son actualmente eficientes. ¿Es eso realmente el caso? Muchas veces los datos esporádicos que se presentan tienen un sesgo muy marcado porque no se considera un principio económico tan sencillo como el de "costo de oportunidad". Si alguien trabaja en una empresa militar con un sueldo a cargo del Ministerio de Defensa y no de la empresa, es evidente que los resultados de esta última van a ser positivos, pero qué ocurre si se le carga a la empresa todos los costos en que realmente incurre, independientemente de quién los consuma. Si los resultados son positivos, tanto mejor para el país, pero esto tiene que ser público y transparente. 
3.- Hay que aclarar todo el tema de los costos salariales en las Fuerzas Armadas. Generalmente se plantean ante la opinión pública sueldos muy (muy) bajos, pero, ¿esa es la realidad? ¿Se está contabilizando de manera adecuada? ¿Acaso el sueldo militar no debe incluir también todos los gastos en que las personas no incurren: vivienda, alimentación, etc.? Hay que poner orden en ese aspecto. Miremos las cosas de frente si queremos discutir seriamente estos temas: las personas que llegan a altos rangos en la institución armada (coroneles, generales y equivalentes en otras ramas), tienen un nivel de vida muy satisfactorio (y así debe ser, puesto que han hecho los méritos suficientes para alcanzar puestos altos en instituciones importantes para el país), pero eso debe quedar en claro.

4.- Las Fuerzas Armadas realizan funciones sociales y de desarrollo importantes, sobre todo en zonas marginales del país, donde casi solamente su personal tiene acceso y contacto real con la población. Pues bien, estas funciones deben enmarcarse dentro de ciertos parámetros:

Deben ser valoradas, para incluir dicho valor dentro de los Presupuestos nacionales. Debemos identificar con claridad cuánto del costo que representan las Fuerzas Armadas para el país, se puede compensar con el ahorro en actividades que si no las realizaran los militares, alguien tendría que hacerlas, invirtiendo recursos.

Requerimos del análisis de eficiencia para saber si esa es la mejor manera de cumplir con dichas funciones sociales y de desarrollo. Esto puede llevar a aumentar o disminuir la participación militar en esas actividades. La evaluación de eficiencia debe incluir la manera en que los militares utilizan su tiempo dentro de los cuarteles y fuera de ellos, los costos implícitos y los resultados que se alcancen. No existe nada peor en el país, como el sistema actual en el que muchas instituciones estatales se encargan de las mismas actividades y en los mismos lugares ¿Quién sabe si el resultado de esta reflexión, no debe ser que las Fuerzas Armadas se encarguen directamente de ciertas funciones en ciertas zonas (donde su rol es superior a 
los de los Ministerios de Educación y de Salud) y se les entregue el presupuesto correspondiente?

5.- No podemos dejar de mencionar el tema de la corrupción. ¿Existe en las Fuerzas Armadas? ¿Qué hacemos para enfrentarla en el caso de que la respuesta es positiva? ¿Es un tema intocable simplemente "porque afecta la imagen de una institución que requiere mantenerse inmaculada ante la opinión pública para ejercer su rol adecuadamente'?

Como vemos, hay mucho que hacer para mejorar la calidad y la cantidad de la vinculación económica de las Fuerzas Armadas con la sociedad. Hay mucho que hacer, pero hay que empezar a caminar. 
